IMPACT OF DELAYED PRICE CONTRACTS ON CORN BASIS:

A CONCEPTUAL MODEL AND A CASE STUDY FOR AN OHIO LOCAL MARKET

By

E. Dean Baldwin, Cameron S. Thraen and Donald W. Larson*

*Associate Professor, Assistant Professor and Professor, respectively, Department of Agricultural Economics and Rural Sociology, The Ohio State University, September 1986 


\section{IMPACT OF DELAYED PRICE CONTRACTS ON CORN BASIS: \\ A CONCEPTUAL MODEL AND A CASE STUDY FOR AN OHIO LOCAL MARKET}

\section{INTRODUCTION}

Structural changes in grain markets, the lack of on-farm storage, increased farm price variability and the desire to separate the harvest delivery function from the pricing function have fostered the development and use of delayed price (DP) as a method of exchange in grain markets. Delayed price is a marketing agreement whereby the seller (often the farmer) delivers grain and passes title to the purchaser (often a grain elevator), but reserves the right to price grain at some future date [Wills]. The seller prices grain in some agreed-to future time period by accepting the buyer's price bid for cash grain sales in that future time period.

Until the seller elects to price the grain, prices vary as new market equilibriums are established. The seller of DP grain accepts a "long" cash speculative position and earns speculative profits as price increases. Sellers enter into delayed price agreements when storage is in short supply and futures prices are forecast to increase or basis is expected to strengthen.

In contrast, the buyer of DP grain accepts a "short" cash speculative position and earns speculative profits as price decreases. The buyer of DP grain minimizes futures price and basis risks associated with the speculative position by taking an offsetting long position in either the cash or futures market. Offsetting long cash market positions include storing grain, buying grain via a forward contract and 
selling grain via a DP contract. Offsetting long futures market positions include buying grain via a futures contract or a commodity option.

All price and basis risks are eliminated when the elevator or buyer elects to offset the short DP acquisition with a long cash marketing position. Selecting a long futures position eliminates the price risk, but not the basis risk. In the latter case, the buyer must forecast basis movements in an attempt to earn an acceptable margin for performing the merchandizing function. Buyers minimize basis risk by charging the seller a DP service fee equaling the expected change in basis.

The delayed price selling method is used by farmers and elevators in at least 25 states. In 1977, for example, Ohio corn DP sales equaled 16 percent of all corn marketings, DP sales in five states from the Midwest equaled 8.5 percent of all corn marketings and DP sales in seven states from the South equaled 2.2 percent of all corn marketings [Smith and Baldwin]. By 1982, Ohio farmers had expanded their use of DP corn sales to 28 percent of all corn marketings. In addition, 32 percent of all soybeans and 26 percent of all wheat marketings in ohio were sold via DP [Ohio Grain Flow Study].

The widespread use of DP in the Midwest and South may subject large numbers of farmers to additional financial risk as this selling method separates the transfer of title from the pricing function. In addition, this selling method may influence price levels paid to farmers or may influence the local market basis. Because of the potential impact of DP on price levels and financial risk, the advantages and disadvantages of 
this selling method are being debated by farm organizations, members of the grain trade and agricultural economists [ IFBCD, Good, McKinstray, Sadler, Sharp, Weidner, Wills and Wisner].

Proponents of DP argue that the DP selling method improves grain merchandising operational efficiencies resulting in higher prices paid to farmers. The opponents argue that a local supply effect results in lower prices paid to farmers, and an unacceptable financial risk; the farmer is an unsecured creditor to the elevator until the grain is priced. These debates are contributing to the passage of state grain marketing legislation in Ohio, and other states to regulate DP contracts to better protect farmers and grain traders. Although the debate is intensifying and is circulating throughout the Midwest and South, the advantages and disadvantages of DP have been discussed only in the popular press and by legislators. To date, researchers have not examined the issues conceptually or empirically.

This article develops a conceptual model to explain the economic effect of the DP selling method on prices paid to corn farmers by an elevator (the effect on local bases) and tests the theory using Granger's causality test. The empirical work focuses on the lagged relationship between DP sales (bushels of corn bought from farmers by one grain handler in a local market) and the resulting strengths or weaknesses in the local harvest basis for the 1977 to 1982 period in Ohio. 1/ The harvest basis (October through December) is selected because most DP contracts are signed during this period [Smith and Baldwin]. Granger's causality test is used in this analysis to test autocorrelation and the lagged relationship between DP contracts and basis [Ashley et al., Barnett et al., and Granger]. In the following 
sections of this paper, the DP arguments published in the popular literature are reviewed and are examined within the context of a conceptual model, the methodology and data are presented, the empirical findings are examined and the conclusions and implications follow.

DELAYED PRICE CONTROVERSY

The delayed price contract originated in the late 1940 s in central Illinois. The concept received only limited attention until the 1960s when it was introduced to farmers in northwestern ohio. With the increasing shortage of on-farm and grain elevator storage space and the introduction of unit trains, DP became a popular selling method throughout Ohio, the Midwest and South during the 1970s [Smith and Baldwin].

Since DP was advertised as an alternative to commercial grain storage, this contract became synonymous with storage and was often misused by farmers and grain handlers. Opponents of DP articulated the differences between DP and commercial storage contracts focusing their attention on the financial issue. That is, the farmer is an unsecured creditor for the grain handler from the time the DP contract is signed and until the grain is priced.

The proponents of DP did not debate the financial issue. Instead, they argued that the operational efficiency benefits (operational efficiency effect) from DP more than offset the increased financial risk assumed by the farmer. That is, the utilization of DP allows grain handlers to lower costs by more efficiently performing the transportation, financial, storage and merchandizing functions. Since they assumed that the use of DP contracts lowers operating costs, the proponents argued that farmers are paid higher grain prices as the local basis strengthens in the post harvest period [McKinstray, OFBF]. 
Opponents countered the operational efficiency effect argument by reasoning that DP is inherently expensive, since this marketing method transfers the storage function from the production areas to processing and export centers [Good and Wi1ls]. Further, they argued that the transfer of title from the farmer to the grain handler increases the available supply of grain (supply effect) to the market at critical times during the year. The storage inefficiencies and the increase in supply diminish prices paid to farmers who are selling via cash contracts or weakens the local basis [Good and Wills].

\section{Conceptual Mode1}

The supply and efficiency effects of DP on corn prices are examined graphically in Figure 1. It is assumed that the market equilibrium is established prior to the introduction of DP contracts. Then, the supply effects of DP are introduced by substituting, both cash grain sales and stored grain for DP sales. Finally, the efficiency effect of DP is examined.

In Figure 1, the markets are in equilibrium for cash grain sales where DP contracts are not traded in the local market, an arena where elevators and processors buy corn from farmers. Panel A of Figure 1 portrays the quantity of corn stored by farmers in time period $(t)$. It is assumed that the total quantity supplied at harvest $\left(\bar{S}_{L} t\right)$ in the local market is fixed.2/ The local storage function $\left(I_{L}{ }^{t}\right)$ is inversely related to price. In this example, the quantity stored equals ( $Q_{S}{ }^{t L}$ ) when price equals zero and zero when price equals $\left(P_{L}^{\prime \prime} t\right)$. 
In Panel $B$ of Figure 1, the total quantity of corn supplied by farmers in the local market is given by the function $\left(S_{L} m t\right)$. When all corn sold is by cash sales, the function $\left(S_{L}{ }^{m t}\right)$ is equivalent to the cash grain sales function $\left(S_{L}{ }^{c t}\right)$. Both $\left(S_{L}{ }^{m t}\right)$ and $\left(S_{L}{ }^{c t}\right)$ are functions of local market price.

When the local market is in equilibrium, quantity $\left(\mathrm{Q}_{\mathrm{L}}^{\mathrm{mt}}\right)$ is exchanged at price $\left(P_{L}^{t}\right)$ and quantity $\left(Q_{I}{ }^{t}\right)$ is stored (Figure 1, Panels $A$ and $B)$. By definition, this $\left(Q_{L}{ }^{m}\right)$ plus $\left(Q_{I}{ }^{t}\right)$ equals the total local harvest supply $\left(\bar{S}_{L}{ }^{t}\right)$.

Panel $\mathrm{C}$ of Figure 1 portrays the regional market. It is assumed that this is a competitive market in which the regional supply function $\left(S_{R}{ }^{t}\right)$ is comprised of the sum of the individual local market supply curves. The $\mathrm{X}$ axis in the regional market is shifted below the corresponding $X$ axis of the local market and represents the cost to transfer corn from the local market to the regional market (OZ). $3 /$ Based on these assumptions, $\left(Q_{R}{ }^{t}\right)$ is exchanged in the regional market at price $\left(P_{R}{ }^{t}\right)$

\section{Specific Assumptions for DP Analysis}

For this analysis, it is assumed that farmers have three marketing alternatives - sell corn at harvest (cash sale contract, CS), store for future sale (store), or sell via a DP contract. 4/ A competitive bid-offer market exists. Grain handlers bid prices to farmers by subtracting the local basis from the nearby futures price. As the local market supply-demand relationships change, grain handlers vary the local bid by strengthening or weakening the local basis. $5,6 /$ The impact of DP contracts on price or basis is examined by first substituting the DP 
contract for the CS contract and then for storage. The impact of the assumed improvement in operational efficiency (the proponents argument) on price or basis is then examined.7/

Substitution of DP Contracts for CS Contracts in the Harvest Period Assume that farmers substitute DP contracts for CS contracts in order to capture higher prices in a future time period. The quantity of corn sold via DP contracts will be a direct function of future price expectations and an indirect function of the elevator's DP service charge. Farmers will increasingly substitute DP sales for CS contracts as price expectations for the future increase and the elevator's current DP service charges decrease.

With the total local supply of corn at harvest assumed to be fixed at $\left(Q_{S}{ }^{t L}\right)$ and the substitution of DP contracts for storage excluded, each bushel of corn marketed via DP diminishes cash grain sales by one bushel in the local market. The quantity of corn sold via DP contracts in response to future price expectations and the DP service fee is $\mathrm{Q}_{\mathrm{L}}{ }^{\prime m} \mathrm{t}_{\mathrm{L}} \mathrm{mt}$, and the cS function shifts to $\mathrm{S}_{\mathrm{L}}{ }^{\prime c t}$ (Figure 2, Panel B). The quantity of DP corn sales $\left(Q_{L}{ }^{\prime m t} Q_{L} m t\right)$ is not priced by the seller or farmer but in effect moves through the local market at price $\left(P_{L}{ }^{t}\right)$. The total marketing function $\left(S_{L}{ }^{m t}\right)$ and the demand function $\left(D_{L}{ }^{t}\right)$ remain unchanged. The elevator ensures that it pays the farmer the current local market price $\left(P_{L}^{t}\right)$ for the DP grain by selling the DP grain in the regional market at price $\left(P_{R}{ }^{t}\right)$ and hedging its position in the futures market.

Since DP and cash grain are exchanged in the local market for price $\left(P_{L}{ }^{t}\right)$, the effective local demand function is the line segment $\left(P_{L}{ }^{t} A D_{L}^{t}\right)$ (Figure 2, Pane1 B). Cash grain sales are in equilibrium as 
the quantity supplied equals quantity demanded (OQ ${ }_{L}$ "mt) at price $\left(P_{L}{ }^{t}\right)$ and the quantity stored equals $\left(O Q_{I}{ }^{t}\right)$ (Figure 2, Panels $A$ and $B$ ). Since the regional supply and demand curves are unchanged, the equilibrium conditions are $\left(P_{R}^{t}\right)$ and $\left(Q_{R}^{t}\right)$, respectively (Figures 2, Pane1 $C$ ). Assuming a one-for-one bushel substitution of DP sales for CS occurs, the total supply of grain is fixed and DP sales are not substituted for stored grain, the market equilibrium prices in the local and regional markets are not modified. Therefore, when DP substitutes only for $\mathrm{CS}$ on a one-to-one basis, there are no local nor regional price effects. In this case, DP has no effect on the local basis.

\section{Substitution of DP Sales for Storage in the Harvest Period}

In this case, farmers substitute DP sales for storage in order to speculate on price movement while avoiding the risk of product deterioration and the associated storage cost or commercial storage charge [Good]. Each additional bushel of corn marketed via a DP contract decreases the grain stored by farmers by one bushel in the local market.

The substitution of DP sales for stored grain shifts the storage function from $\left(I_{L}{ }^{t}\right)$ to $\left(I_{L}{ }^{t}\right)$, and the marketed grain supply function shifts from $\left(S_{L}{ }^{m t}\right.$ ) to $\left(S_{L}{ }^{\prime} m t\right)$ (Figure 1 , Panels $A$ and $B$ ). The new equilibrium price and quantity are $\left(\mathrm{P}_{\mathrm{L}}{ }^{\prime} \mathrm{t}\right)$ and $\left(\mathrm{Q}_{\mathrm{L}}{ }^{\prime}\right.$ 'mt $)$ in the local market. The demand function shifts to $\left(P_{L}{ }^{\prime} t A^{\prime} D_{L}{ }^{t}\right)$.

Based on the cash sales supply function $\left(\mathrm{S}_{\mathrm{L}}{ }^{\prime} \mathrm{ct}\right)$, the farmer supplies $\left(O Q_{L}\right.$ '' 'mt) of cash sales, which is a decrease in the quantity supplied equal to $\left(Q_{L}{ }^{\prime \prime \prime ' m t ~} Q_{L}\right.$ 'mt). Cash sales or the quantity supplied $\left(O Q_{L}\right.$ ''''mt) equals the quantity demanded at price $\left(P_{L}{ }^{\prime} t\right)$ where the cash sales supply function $\left(S_{L}{ }^{\prime} c t\right.$ ) intersects the demand function $\left(P_{L}{ }^{\prime} t_{A}{ }^{\prime} D_{L}{ }^{t}\right)$. The residual supply of grain or delayed price grain 
$\left(Q_{L}{ }^{\prime \prime \prime ' m t} Q_{L}{ }^{\prime \prime \prime m t}\right)$ is not priced by farmers, but is effectively priced at $\left(P_{L}{ }^{\prime} t\right)$ assuring that the elevator stores the grain or sells in the regional market and takes a hedge position. The quantity stored by farmers at price $\left(P_{L}{ }^{\prime}\right)$ is $\left(O Q_{I}{ }^{\prime} t\right)$ (Figure 1 , Panels $A$ and $B$ ).

Two outcomes are possible in the regional market. First, if grain elevators store the additional DP acquisition in the local market, the regional supply function $\left(S_{R}{ }^{t}\right)$ and the equilibrium conditions $\left(P_{R}{ }^{t}, O Q_{R}{ }^{t}\right)$ are unchanged. Since the equilibrium price in the local market decreases, the price differential between the local market and the regional market increases by (BC) (Figure 1 , Panels $B$ and $C$ ). This differential $(B C)$ represents the theoretical storage cost to transfer grain through time until it is sold in the regional market. The total differential between the two markets is $(B C)$, storage cost, plus (OZ), transportation cost.

For the second outcome, the grain handler may transfer the additional DP grain to the regional market which shifts the regional supply curve to $\left(S_{R}{ }^{t}\right)$, (Figure 1 , Panel $c$ ). This outcome decreases the equilibrium price in the regional market to $\left(P_{R}{ }^{t}\right)$ and increases the quantity supplied and demanded to $\left(0 Q_{R}{ }^{\prime} t\right)$. The price differential between the two markets again equals (OZ).

A partial transfer of DP grain into the regional market shifts the regional supply function to a location in between $\left(S_{R}{ }^{t}\right)$ and $\left(S_{R}{ }^{\prime}\right)$ resulting in an equilibrium price that is greater than $\left(P_{R}{ }^{t}\right)$ and less than $\left(P_{R}{ }^{t}\right)$. The equilibrium conditions in the local market would be unchanged; however, the quantity stored by grain elevators would be greater than zero but less than $\left(\mathrm{Q}_{\mathrm{L}}{ }^{\mathrm{mt}} \mathrm{Q}_{\mathrm{L}}{ }^{\prime \prime \prime m t}+\mathrm{Q}_{\mathrm{L}}{ }^{\prime \prime \prime m t} \mathrm{Q}_{\mathrm{L}}{ }^{\prime \prime m t}\right)$. 
The substitution of the DP selling method for the storage function increases the supply of grain in the local market establishing a lower price or a weaker basis. In addition, DP sales are substituted for cash grain sales because the quantity of grain sold decreases with the price decrease. This substitution effect substantiates the argument that the introduction of DP sales weakens the basis in the local market. The theoretical impact of DP on price and basis is indeterminant for the regional market.

\section{Operational Efficiency Effect}

Grain handlers tender delayed price contracts to farmers to acquire title to corn, to extract corn from storage and to acquire interest free short term unsecured loans. The quantity of corn bought via DP contracts is a direct function of the buyers' existing and expected sales commitments and the anticipated improvement in operational efficiency from a reduction in financial, storage and transportation costs. Financial costs decline because the grain handler is acquiring an unsecured interest free loan until the farmer prices the corn. Storage and transportation costs decline because the grain handler owns the grain making it possible to more efficiently schedule the use of transportation and storage equipment.

Prior to the introduction of the operational efficiency effect, it is assumed that the DP substitution effects for cash grain sales and stored grain are in place. Further, the assumed equilibrium in the regional market is established by the demand function $\left(D_{R}{ }^{t}\right)$ and the supply function $\left(S_{R}{ }^{\prime} t\right)$ (Figure 1, Panel $C$ ). Grain elevators, then, are not storing the additional DP grain from the storage effect. In equilibrium, the regional grain price equals $\left(P_{R}{ }^{\prime} t\right)$, the quantity traded 
equals $\left(O Q_{R}{ }^{\prime} t\right)$ and the price differential between the regional and local markets is (OZ).

In the local market, the equilibrium is established by the market supply function $\left(S_{L}{ }^{m t}\right)$ and the demand function $\left(P_{L}{ }^{\prime} t_{A}{ }^{\prime} D_{L}{ }^{t}\right)$; the quantity stored by farmers is determined from the storage function $\left(I_{L}{ }^{t} t\right)$. In equilibrium, the local grain price equals $\left(P_{L}{ }^{\prime} t\right)$, cash sales equal $\left(O Q_{L} " ' m t\right)$, DP sales equal $\left(Q_{L}{ }^{\prime \prime \prime} m{ } Q_{L}{ }^{\prime \prime} m t\right)$, the total quantity of marketed corn equals $\left(O_{L}{ }^{\prime \prime} ' m t\right)$ and the quantity stored equals $\left(O Q_{I}{ }^{\prime \prime} t\right)$.

To illustrate the operational efficiency effect, assume that the competitive forces in the market transfer the benefits back to the seller or farmer in the local market as higher prices or a stronger basis. 8 for this case, the demand curve in the local market theoretically increases to $\left(D_{L}{ }^{\prime} t\right)$ (Figure 4 , Panel B.)

Prices in the local market increase to $\left(P_{L}{ }^{t}\right)$, the total quantity of marketed corn increases to $\left(\mathrm{QQ}_{\mathrm{L}}{ }^{\prime \prime}{ }^{\prime \prime}\right.$ 'mt $)$, the quantity of corn stored by farmers decreases to $\left(O Q_{I}{ }^{\prime} t\right)$, the quantity of cash grain sales in the local market increases to $\left(\mathrm{OQ}_{\mathrm{L}}{ }^{\prime \prime} \mathrm{mt}\right)$ ) and the quantity $\left(\mathrm{Q}_{\mathrm{L}}{ }^{\prime \prime m t} \mathrm{Q}_{\mathrm{L}}{ }^{\prime \prime \prime \prime ' m t}\right)$ is exchanged via DP sales. Higher prices paid to farmers from the operational efficiency effect decreases the quantity of corn stored by farmers and increases the quantity of cash and DP sales. If grain handlers store the newly acquired grain, prices in the regional market are unchanged. Transferring all or part of the additional grain to the regional market would alternatively decrease the price as the regional supply function shifts to the right. Based on the stated assumptions, the operational efficiency effect supports the view that local price or basis is strengthened. 
The potential collective impact of the substitution and operational efficiency effects on price or basis in the local market is inconclusive. If the hypothetical change in the supply function ( $\mathrm{s}_{\mathrm{L}}{ }^{\prime} \mathrm{mt}$ ) from the substitution effect is greater than (less than) the hypothetical change in the demand function to $\left(D_{L}{ }^{\prime} t\right)$ from the efficiency effect, the local market price decreases (increases) or basis weakens (strengthens).

\section{Methodology and Data}

The statistical causality test proposed by Granger is used to determine the impact of DP sales on basis for a local elevator. 9 / If basis weakens (strengthens) as DP sales increase for a specific year, the substitution (efficiency) effects are greater than the efficiency (substitution) effect. If basis does not change as DP sales increase for a specific year, this implies that the substitution effects offset the efficiency effect or that no lagged relationship exists.

These lagged relationships are examined using the definition of causality as set out by Granger. In the Granger sense X (DP) causes $Y$ (Basis), if knowledge of $X$ statistically improves the ability to predict $Y$, after accounting for the information contained in past values of $Y$ [Granger, 1969]. In this sense, questions as to the "true meaning of causality are sidestepped" and causality between variables is explicitly defined. Causality can be either undirectional, bidirectional, and/or instantaneous. Granger proposed the following general test for causality between two stationary time series:

$$
\begin{aligned}
\text { (1) } x_{t}=\sum_{j=1}^{M} a_{j} x_{t-j}+\sum_{i=1}^{n} b_{i} Y_{t-i}+e_{t} \\
\text { (2) } Y_{t}=\sum_{j=1}^{M} c_{j} Y_{t-j}+\sum_{i=1}^{n} d_{i} X_{t-i}+u_{t}
\end{aligned}
$$


where the classical assumptions on the stochastic properties of $e$ and $u$ are expected to hold. The parameters of (1) and (2) are estimated by applying ordinary least squares. The test of causality is then defined on the joint significance of the estimated parameter sets $a, b, c$, and $d$ [Granger, 1969]. For example, if the set $b$ is not significantly different from zero, then the null hypothesis that $Y$ does not cause $X$ is accepted. Likewise, if the set $d$ were not significantly different from zero, then the null hypothesis that $\mathrm{X}$ does not cause $\mathrm{Y}$ is not accepted. In this case the two series would be sample-wise independent.

This notion of causality was modified by Sims to include the concept that the future does not cause the past and that a stochastic stationary series $Y$ "can be expressed as a distributed lag function of current and past (but not future) $\mathrm{X}, \ldots$, if and only if, $Y$ does not cause $X$ in the Granger sense [Sims, 1979, pp. 444-445]. In recognition of the effects of serial correlation of the residual series on the significance test, Sims proposes a method to filter the data to correct for this. Keeping in mind the advantages and limitations of this notion, as identified by Geweke, Meese and Dent, the Sims procedure was chosen to investigate the statistical causality or the lagged relationship between DP and the local market basis.

The empirical procedure consists of regressing the current observations of the local harvest basis (the dependent variable) on its own past observations as well as past observations of the number of bushels of corn delivered via DP sales. To estimate the causal structure annually for each of the harvest periods from 1977 through 1982 (excluding 1979), the parameters of the following dynamic regression are estimated with ordinary least squares: $10 /$ 
(3) $-B_{t}=a_{10}+\sum_{i=1}^{m} a_{1 i}{ }^{B} t_{t-1}+\sum_{1 t}$
(4) $-B_{t}=a_{20}+\sum_{i-1}^{m} a_{2 i}{ }^{B} t-1+\sum_{t=j}^{n} \gamma_{j} D P{ }_{t-j}+\Sigma_{2 t} ;$

where $B_{t}=$ basis in cents per bushel under the nearby futures in period t. 111

$D P_{i-j}=$ the number of bushels of corn delivered via DP contracts in period $t$

$m=$ total number of lagged periods of basis

$\mathrm{n}=$ total number of lagged periods of DP sales

$i$ and $j=i$ th and $j$ th lagged periods.

$a_{10}, a_{20}$ and $j$ are dynamic regression parameters, and $1 t$ and $2 t$ are white noise residuals. $12 /$

Values of $m$ and $n$ in equations (3) and (4) may be chosen from apriori knowledge of leads and lags or via a joint $\mathrm{F}$ test [Barnett et al.]. Because of the absence of prior knowledge, the $F$ test was used to identify the significant number of respective lags for both basis and DP. The selection of too few or too many lag variables may result in significant serial correlation in the error structure and bias the $F$ and $t$ statistics [Pierce and Haugh]. Thus, it may be concluded that a lagged relationship exists between DP and basis when, in fact, this relationship does not exist. Two tests are performed to detect serial correlation in the error structure. The first test is an F-test based on the estimated residuals obtained from the least squares regressions (equations 3 and 4). An autoregression of these residuals lagged five periods is estimated by ordinary least squares (OLS) as follows: 
(5) $e_{t}=a_{0}+\sum_{i=1}^{S} i_{t-1}$

where: $\quad e_{t}=$ current residual series estimated by oLs

$$
\begin{aligned}
a_{0}, b_{i} & =\text { parameter estimates } \\
i & =i t h \text { lagged residual }
\end{aligned}
$$

The significance of the estimated parametes can be judged by the joint F-Test. In addition, the Box and Pierce $Q$ test is also used to detect significant serial correlation (Barnett et al.).

Should these tests reveal significant serial correlation in any of the residuals, a filter of the following form is used to transform both variable series to white noise [Sims].

(6) $(I-K L)^{N}$

where $\mathrm{K}=.75$

$\mathrm{L}=1 \mathrm{ag}$ operator

$\mathrm{N}=$ number of lags

The order of filter needed to "whiten" the series is determined by checking the order of significant coefficients on the lagged residuals in the autoregression (equation 5). If the estimated residual lagged four periods is significant, then a fourth order expansion of Sims filter is used [Bishop]. If a Sims value of .75 does not "whiten" the series, different values of $k$ are tried. Models in which significant serial correlation cannot be removed are excluded from the causality tests. 
Data

The lagged relationship between DP and basis is determined for each harvest period (October through December) from 1977 - 1982 (excluding 1979), using the December futures corn basis as the dependent variable. For each of the five years, daily cash corn price bids to dealers were collected from one northwestern Ohio elevator and were used as a proxy for daily bids to farmers.13, 14/ In addition, the daily volume of DP corn deliveries (the independent variable) and daily delayed price service fees were recorded. Daily December futures price data were obtained from Chicago Board of Trade publications. The daily December basis was calculated by subtracting the futures price from the cash corn price bid [Neely].

To broaden the empirical analysis, attempts were made to collect similar data from other firms; however, daily delayed price sales data were unavailable or were incomplete. The daily corn price bids and DP service charge data collected from the one firm should represent local market conditions as a large number of other competing firms in the market area also provide DP contracts as well as other similar marketing alternatives and services to their customers. Competitive pressure, then, would cause price bids and DP service charges of this one firm to equal or approach those generated by the local market economic conditions.

\section{Empirical Results}

The causality test described in the methodology section was completed for the 1977 through 1982 period. The dependent variable 
(basis) is regressed on past values of basis, lagged the appropriate number of periods, and then is estimated with the lagged independent variables (DP) added to the model.

Based on the $F$ tests for each year, the selected number of lags for bases equaled two for 1978, 1980 and 1982, respectively, five for 1977 and seven for 1981 (Table 1). The selected number of lags for DP sales equaled zero for 1978, two for 1981, three for 1977, four for 1980 and six for 1982. For the periods 1978 through 1982, using the Box-Pierce Q statistic, serial correlation was not a problem. For 1977, based on the $Q$ statistic, serial correlation was significant. After applying Sim's filtering procedure, white noise could not be established for the series. Therefore, the period 1977 was excluded from the analysis.

A second $F$ test as reported in Table 2 is performed to test the nul1 hypothesis that the independent DP variables jointly are insignificant in the model. This $\mathrm{F}$ test is performed by calculating the reduction in the sum of squared error (SSE) resulting from the addition of the independent DP variables to the equation. If the F statistic is significant, the nul1 hypothesis that the reduction in the SSE is due to random chance is rejected in favor of the alternative hypothesis that the reduction in the standard error is due to the addition of the independent DP variables. Therefore, a significant F statistic indicates that the independent DP variables "cause" changes in the dependent basis variable in the Granger sense.

There are four possible causal outcomes between DP and Basis. These are i) basis causes DP, $i i)$ DP causes basis or the substitution effects (efficiency effect) are greater than the efficiency effect (substitution effect), iii) a causal relationship does not exist or the 
substitution effects offset the efficiency effect, and iv) a bidirectional flow is present (basis and DP simultaneously cause each other). Since the F tests for Basis causes DP were not significant, we conclude that basis does not cause DP in the Granger sense (Table 2). Further, a bidirectional flow was not evident in any of the models tested [Neely]. $D P \rightarrow B(1981$ and 1982), DP Causes Basis for 1981 and 1982

The significant $F$ test of 5.2 for the 1981 model and 2.27 for the 1982 model indicates that DP causes basis in the Granger sense in each of these years (Table 2). By setting the delayed price independent lagged variables in each of the models to a value greater than zero (shocking the system), it can be determined whether basis weakens (substitution effects are greater than the efficiency effect) or strengthens (efficiency effect is greater than the substitution effects). 1981 Time Period

For 1981 it is assumed that this elevator buys 5 million bushels of DP grain in time periods one and two, respectively. A relatively large value is assigned to the DP variables to graphically illustrate the substitution and efficiency effects. That is, the lagged DP variable coefficients generated by the 1981 mode are relatively smal1 (Table 1). Further, it is assumed that all lagged basis variables equal zero; therefore, in period one basis equals -2.07 cents or is equal to the "a" coefficient (Figure 2 and Table 1). In time period two, the increase in DP acquisitions weakens the basis. Therefore, the substitution effect is greater than the efficiency effect or DP sales by farmers are being substituted for stored grain (Figure 1). In time periods two through four, the basis strengthens or the efficiency effect is greater than the substitution effects. In time period five, the DP lagged variables 
equal zero and basis is again equal to the "a" coefficient. Aggregating across the five time periods, basis strengthens more than it weakens; therefore, the total efficiency effect is greater than the substitution effects (Figure 2).

Structurally, the following may explain why the aggregated efficiency effect was greater than the substitution effects for 1981 . Corn exports and domestic demand were relatively large [Henderson and USDA]. Total corn production in Ohio declined from 440 million bushels in 1980 to 360 million in 1981 , and soybean production also declined. Therefore, the total supply of corn and soybeans equaled $96 \%$ of the total storage capacity. Given the increase in demand, the decrease in supply and an adequate supply of storage space, the elevator may have passed back all or part of the improved operational efficiency effect as higher prices paid to farmers to acquire more corn via cash sales to meet its export and domestic demand commitments. The zero DP charge in October 1981 and the corresponding DP charges for November and December suggest that this elevator had to stimulate grain movements to acquire an adequate supply of corn to meet demand commitments (Table 3). 1982 Time Period

For 1982 , it is assumed that the elevator buys 500 thousand bushels of corn during periods one and two, respectively. A smaller value is assigned to the 1982 DP lagged variables relative to 1981 to graphically illustrate the substitution and efficiency effects (Figure 2). This is possible because the lagged DP variable coefficients generated by the 1982 model are relatively larger than those generated for 1981 . 
Further, it takes nine periods to illustrate the aggregated effects for 1982 relative to five for 1981 as the 1982 model contains six DP lagged variables while the 1981 model contained only two lagged DP variables.

In period one, basis equals -2.08 cents or the "a" coefficient for the 1982 model (Figure 2 and Table 1). In time period two, the increase in DP acquisitions weakens the basis, or the substitution effects are greater than the efficiency effect. Thereafter, basis strengthen (the efficiency effect is greater than the substitution effects for periods three through eight) until the DP lagged variables again equal zero. For the nine periods, the total aggregate efficiency effect is greater than the substitution effects.

Structurally, the following may explain why the aggregated efficiency effect was greater than the substitution effects in 1982 . Corn exports and domestic demand were relatively large. Ohio had a record corn production in excess of 456 million bushels. Since soybean production was also relatively large, the total supply of corn and soybeans was $121 \%$ of available storage capacity. Farmers acquired CCC loans on relatively large quantities of corn so the available "free supply" remained relatively low. Given the relatively large demand and the relatively small free supply of corn, the elevator may have passed back part or all of the improved operational efficiency effect as higher prices paid to farmers to acquire corn via cash sales to meet its total demand commitments .

During October, when the supply of corn and soybeans exceeded the available storage space, DP charges to farmers were relatively large (Table 3). During November and December, the DP charges were lowered 
significantly to move grain out of farm storage and into the marketing channels to meet the elevator's sales commitments.

No Causal Relationship (1978 and 1980)

In two years (1978 and 1980) both F statistics are insignificant at the .05 level, implying no causal relationship between DP sales and harvest basis (Table 2). This implies that the substitution effects equaled the efficiency effect or that no causal relationship exists (the substitution and efficiency effects each equal zero).

\section{Time Period}

In 1978, production of corn in Ohio was relatively low, equaling 379 million bushels. Since soybean production was also relatively small, adequate storage space may have been available. Most of the corn supply was available for sale as the federal feed grain program was curtailed and most Ohio farmers did not participate. These data suggest that farmers may not have substituted stored corn for DP sales in 1978. Therefore, basis would not have weakened in the corn market.

If the supply of corn provided via DP contracts and cash sales equaled the demand for corn, the elevator may not have passed back all or part of the efficiency effect as higher prices to farmers. Therefore, the basis would not have strengthened. The trend in the elevator's DP charges for 1978 nearly equaled the 1982 trend, a period in which many elevators believed that the corn supply was adequate to meet demand (Table 3).

\section{Time Period}

In 1980 , the supply of corn and soybeans was relatively large implying that the demand for storage was increasing and that farmers were forced to move corn via DP and cash sale agreements. Since DP was 
not substituted for stored corn, basis was not weakened. Assuming that the available supply of corn equaled the demand, the elevator may not have passed back all or part of the efficiency effect as higher prices to farmers. Therefore, the basis was not strengthened. The magnitude of the DP charges during the October through December period suggest that, in fact, corn supplies were adequate (Table 3 ).

\section{Conclusions and Implications}

Opponents of DP argue that the widespread use of the DP selling method by farmers weakens the basis in a local grain market. This argument was conceptualized in this paper by substitution of grain sold via the DP selling method for farmer stored grain. A similar substitution of grain sold via the DP selling method for cash grain sales proved to have a neutral effect on basis and cannot be used as an argument to support the views of the opponents.

Proponents of DP argue that the use of the DP selling method by farmers strengthens the basis in a local grain market. Assuming that the hypothesized cost savings from the improved operational efficiency effect are passed back to farmers, this argument was also verified. Alternatively passing the cost savings forward to buyers in a regional market or retaining the cost savings by the elevator has a neutral effect on the basis and cannot be used as an argument to support the views of the proponents

Although the conceptual model supports both the opponent's and proponent's arguments, the aggregated storage substitution effect versus the operational efficiency effect cannot be determined. There are three possible outcomes: i) the substitution effect is greater than the operational efficiency effect causing basis to weaken; ii) the substi- 
tution effect is less than the operational efficiency effect causing basis to strengthen; and $i i i)$ the substitution effect equals the operational efficiency effect and basis is unchanged.

Empirically testing the aggregated impact of the substitution and operational efficiency effects proved to be difficult because of the limited availability of firm data. In one of the five year periods (1977), white noise could not be established for the data series. In two of the five year periods (1980 and 1982), DP sales strengthened the local basis, while in the remaining two years (1978 and 1981), no causal effect could be found.

For the two years in which DP sales strengthened basis, the analysis suggests that the operational efficiency effect was greater than the substitution effects. Thus, the arguments of the proponents were supported. This relationship appears to exist when the demand for corn was large relative to the supply of corn and storage space was relatively available, such as in 1980 and 1982 .

When no causal relationship existed between DP and basis (1978 and 1981), the substitution effects equaled the operational efficiency effect. Relative to the 1980 and 1982 periods, the substitution effects either increased or the operational efficiency effect decreased. This analysis could be used to suggest that the elevator did not always pass part or all of the cost savings from the operational efficiency effect back to farmers in years when an abundant supply of corn was available to meet demand and storage was in relative short supply. This appeared to be the situation for 1978 and 1981. Therefore, it is probable that 
the operational efficiency effect declined as the elevator either passed the cost savings forward to its customers or increased its gross operating margin.

Future empirical research should include data for additional years, more firms and states and employ pooled cross sectional time series analysis. Further, in this research it was assumed that operational efficiencies prevailed. The counter argument proposed by Good that operational inefficiencies exist as grain is stored at non-country sites was not examined. Case studies or engineering studies which examine the cost for storing grain at multiple locations within the marketing channel could resolve this debate. Including these storage cost data in the analysis may result in more consistent empirical findings. Finally, research needs to be undertaken to determine which economic factors (supply, demand, storage, etc.) influence farmers and grain handlers to buy and sell grain via DP. 


\section{FOOTNOTES}

1 Because of data omissions, the impact of DP on the 1979 daily basis is not investigated.

2 Since the total supply function at harvest is perfectly inelastic, it is assumed that in the long run an individual grain handler cannot capture more grain from competitors by offering DP to his customers.

3 Since grain markets are relatively competitive, price differentials between markets are correlated to transportation costs [Sappington, Hill and Baldwin].

4 Although other marketing alternatives such as hedging and forward contracts are available to farmers at harvest time, an evaluation of these alternatives is not required to satisfy the objective of the paper.

5 Cash prices paid to farmers equal the nearby futures price plus the basis where the coefficient assigned to the basis is assumed to be negative $\left(C_{p}=F_{p}+(-B)\right.$. Therefore, if the theoretical analysis identifies a decrease (increase) in the cash price, by definition the basis becomes more (less) negative or weakens (strengthens).

6 A stronger (narrower) basis is defined as an improved basis because the cash price bid to farmers increases in relation to the nearby futures price. A weaker (wider) basis is defined as a deteriorating basis as prices to farmers decrease in relation to the nearby futures price. 
7 To validate whether the DP selling method causes operational inefficiencies [Good and Wills] or efficiencies [McKinstray and OFBF] is beyond the scope of this paper. Instead, the theoretical impact of assumed operational efficiencies is examined.

8 It is recognized that the gain from the efficiency effect could accure to the factor owners and to consumers, depending upon supply and demand elasticities. If all or part is transferred to consumers, the proponent's argument deteriorates.

9 In this analysis, Grangers causality test is not used to represent a structural explanation of basis. Explanation of the differences in causal relationships (DP causes basis in year $Y_{t}$ and no causal relationship is found in Year $Y_{t+1}$ ) among years is examined using reported delayed price service charges. Elevators decrease (increase) the delayed price service charge collected from farmers to encourage the substitution of the delayed price selling period (cash sales or storage) for cash sales or storage (delayed price selling method).

10 Because daily delayed price sales data were incomplete for 1979, data for this year were omitted.

11 For this analysis, the basis coefficient was always negative as $C_{p}{ }^{t}-F_{p}^{t}<0$ where $C_{p}{ }^{t}=$ cash price paid to farmer in time period $t$. $F_{p}{ }^{t}=$ futures price of the nearby futures month in time period $t$.

12 White noise denotes a serially uncorrelated residual series.

13 The use of daily cash bids to dealers as a proxy for farm bids does not effect the results of the study since the difference between the two bids remained constant throughout the study period.

14 To protect the confidentiality of the data, the name and location of the elevator are not identified. 


\section{BIBLIOGRAPHY}

Ashley, R., C.W.J. Granger, and R. Schmalensee. "Advertising and Aggregate Consumption: An Analysis of Causality," Econometrica, Vol. 48, No. 5, July 1980, pp. 1154-1165.

Barnett, Richard C., David A. Bessler and Robert L. Thompson. "The Money Supply and Nominal Agricultural Prices," American Journal of Agricultural Economics, Vol. 65, No. 2, May 1983, pp. 303-307.

Bishop, Robert v. "The Construction and Use of Causality Tests," Agricultural Economics Research, Vol. 31, No. 4, 1979, pp. 1-6.

Bressler, R.G. and R.A. King. Markets, Prices and Interregional Trade, New York: John Wiley and Sons, 1970, p. 91.

Durbin, J. "Testing for Serial Correlation in Least-Squares Regression When Some of the Regressors are Lagged Dependent Variables," Econometrica, Vol. 38, No. 3, May 1970, pp. 410-421.

Gewehe, John, Richard Meese and Warren Dent, "Comparing Alternative Tests of Causality in Temporal Systems," Journal of Econometrica 21(1983) pp. 161-194.

Good, D.L. "Delayed Pricing by Country Elevators," Illinois Agricultural Economics Staff Paper, No. 77 E-22, Department of Agricultural Economics, University of Illinois, Champaign, Illinois, September 1977. Granger, C.W.J. "Investigating Causal Relations by Econometric Models and Cross-Spectral Methods," Econometrica, Vo1. 37, No. 3, July 1969 , pp. 424-38.

Henderson, Dennis R. U.S. Corn Production, Use and Price, Department of Agricultural Economics and Rural Sociology, The Ohio State University, Columbus, Ohio, 1986.

IFBCD. "Deferred Pricing From the Farmers Point of View," Illinois Farm Bureau Commodity Division, Research Report, June 1977. 
McKinstray, Neil. "Grain Merchandiser Defends Deferred Pricing," Big Farmer Entrepreneur, February 1982, pp. 16-19.

Neely, S.H. Economic Analysis of the Delayed Price Selling Method in a Local Corn Harvest Market for Six Different Marketing Years (1977-83), Unpublished M.S. Thesis, Department of Agricultural Economics and Rural Sociology, The Ohio State University, 1984.

Ohio Farm Bureau Federation, Delayed Price Grain Agreements, Study Committee Report to Board of Trustees, Columbus, Ohio, March 30, 1977. Ohio Grain Flow Study, Marketing Systems for Grain and Soybeans, unpub1ished data from a 1982 and 1983 survey of grain elevators, processors, and feed manufacturers, Department of Agricultural Economics and Rural Sociology, The Ohio State University.

Pierce, David A. and Larry D. Haugh. "Causality in Temporal Systems," Journal of Econometrics, Vol. 5, 1977, pp. 265-93.

Pindyck, R.S. and D.L. Rubinfeld. Econometric Models and Economic Forecasts, New York: McGraw Hill, 1976.

Sadler, Curtis D. "Contractual Grain Sales by Illinois Farmers," Unpublished Masters Thesis, Department of Agricultural Economics, University of Illinois, 1978.

Sappington, Charles, Lowel1 D. Hill and E. Dean Baldwin, "Spatial Price Differentials for Corn," Southern Cooperative Bulletin 196, January 1975.

Sharp, John W. "Delayed Price--What is it and How Does it Work?" Cooperative Extension Service Bulletin, The Ohio State University, October 1975 .

Sims, Christopher A. "Money, Income, and Causality," The American Economic Review, Vol. 62, September 1972, pp. 540-52. 
Smith, Russ and E. Dean Baldwin. "The Evolution of Delayed Pricing: From Its Origins Through 1977." Department of Agricultural Economics and Rural Sociology, The Ohio State University, Preliminary Draft, January January 1984

USDA, Ohio Agricultural Statistics, Ohio Crop Reporting Service, Columbus, Ohio, 1978-1983.

Weidner, Tom. "The Questions Behind Delayed Price," Harvest Times, 4th Quarter 1980, pp. 20-24.

Wills, Walter J. "Advantages and Risks of Delayed Grain Pricing," Feedstuffs, 50 (45), October 30, 1978, p. 21.

Wills, Walter J. "Deferred Grain Pricing," Feedstuffs, 48 (18), May 3, 1976.

Wisner, Robert N., C. Phillip Baumel, John Uralize. "An Analysis of Deferred Grain Pricing Contracts," Journal of the American Society of Farm Managers and Rural Appraisers, Inc., Vol. 39, No. 2, October 1975, pp. 9-12. 
Table 1: Regression Estimates for Corn Causal Models for Harvest: Chio, 1977-82a

$$
\text { Mode1 }=-B_{t}=\sum_{i=1}^{M} \alpha_{i} B_{t-i}+\sum_{i=1}^{N} \gamma_{i} D_{t-i}
$$

\begin{tabular}{|c|c|c|c|c|c|c|c|c|c|c|c|}
\hline Year & $\mathrm{F}-\mathrm{val}$ & $\mathrm{R}^{-2}$ & Int. & $B_{t-1}$ & $B_{t-2}$ & $B_{t-3}$ & $B_{t-4}$ & $B_{t-5}$ & $B_{t-6}$ & $B_{t-7}$ & $\mathrm{DP}_{t-1}$ \\
\hline $1977^{\mathrm{b}}$ & 970.3 & .99 & $\begin{array}{r}-.5189 \\
(-1.337)\end{array}$ & $\begin{array}{c}1.356 \\
(11.47)\end{array}$ & $\begin{array}{l}-.2526 \\
(-1.23)\end{array}$ & $\begin{array}{r}.2941 \\
(-1.41)\end{array}$ & $\begin{array}{c}.3279 \\
(1.517)\end{array}$ & $\begin{array}{l}-.1377 \\
(-1.05)\end{array}$ & & & $\begin{array}{c}.000000217 \\
(3.593)\end{array}$ \\
\hline 1978 & 1075.0 & .97 & $\begin{array}{c}.17719 \\
(.642)\end{array}$ & $\begin{array}{c}.2588 \\
(10.02)\end{array}$ & $\begin{array}{c}-2.638 \\
(-2.012)\end{array}$ & & & & & & \\
\hline 1980 & 160.48 & .94 & $\begin{array}{c}-3.954 \\
(-2.546)\end{array}$ & $\begin{array}{c}1.343 \\
(10.24)\end{array}$ & $\begin{array}{c}.4621 \\
(-3.481)\end{array}$ & & & & & & $\begin{array}{c}-.00000107142 \\
(-.003)\end{array}$ \\
\hline 1981 & 269.6 & .98 & $\begin{array}{l}-2.07 \\
(-2.11)\end{array}$ & $\begin{array}{c}1.077 \\
(8.34)\end{array}$ & $\begin{array}{l}.16203 \\
(.797)\end{array}$ & $\begin{array}{l}.1181 \\
(.5877)\end{array}$ & $\begin{array}{l}-.3403 \\
(-1.66)\end{array}$ & $\begin{array}{l}.03865 \\
(.166)\end{array}$ & $\begin{array}{c}-.4496 \\
(-1.948)\end{array}$ & $\begin{array}{c}.3655 \\
(2.614)\end{array}$ & $\begin{array}{c}-.000000174 \\
(-.021)\end{array}$ \\
\hline 1982 & 151.5 & .95 & $\begin{array}{c}-2.08 \\
(-3.44)\end{array}$ & $\begin{array}{r}1.236 \\
(10.39)\end{array}$ & $\begin{array}{c}-.32 \\
(-2.76)\end{array}$ & & & & & & $\begin{array}{l}-.000004664 \\
(-.739)\end{array}$ \\
\hline
\end{tabular}

CONTINUATTION OF INDEPENDENT VARIABLES

\begin{tabular}{|c|c|c|c|c|c|c|}
\hline Year & $\mathrm{DP}_{\mathrm{t}-2}$ & $\mathrm{DP}_{t-3}$ & $\mathrm{DP}_{\mathrm{t}-4}$ & $\mathrm{DP}_{\mathrm{t}-5}$ & $\mathrm{DP}_{\mathrm{t}-6}$ & D.F. \\
\hline 1977 & $\begin{array}{l}.00000217 \\
(.077)\end{array}$ & $\begin{array}{l}.000000982 \\
(3.593)\end{array}$ & & & & 57 \\
\hline 1978 & & & & & & 64 \\
\hline 1980 & $\begin{array}{c}.000007783 \\
(-.363)\end{array}$ & $\begin{array}{r}.0000145 \\
(1.123)\end{array}$ & $\begin{array}{c}-.0000257953 \\
(-2.101)\end{array}$ & & & 57 \\
\hline 1981 & $\begin{array}{l}.000000246 \\
(2.927)\end{array}$ & & & & & 56 \\
\hline 1982 & $\begin{array}{l}.000001339 \\
(-.739)\end{array}$ & $\begin{array}{l}.00000425 \\
(.719)\end{array}$ & $\begin{array}{l}.000004689 \\
(-.79)\end{array}$ & $\begin{array}{l}.00000994 \\
(1.629)\end{array}$ & $\begin{array}{l}.00001297 \\
91.988)\end{array}$ & 54 \\
\hline
\end{tabular}

a 1979 excluded

b 1977 estimates may be biased due to severe autocorrelation, Sim's Filter technique did not eliminate autocorrelation.

t-statistics for coefficients appear in parenthesis below relevant coefficients. 
Table 2: Causality Tests With Delayed Price Corn Receipts and Basis for Harvest Periods: Ohio, 1977-82a

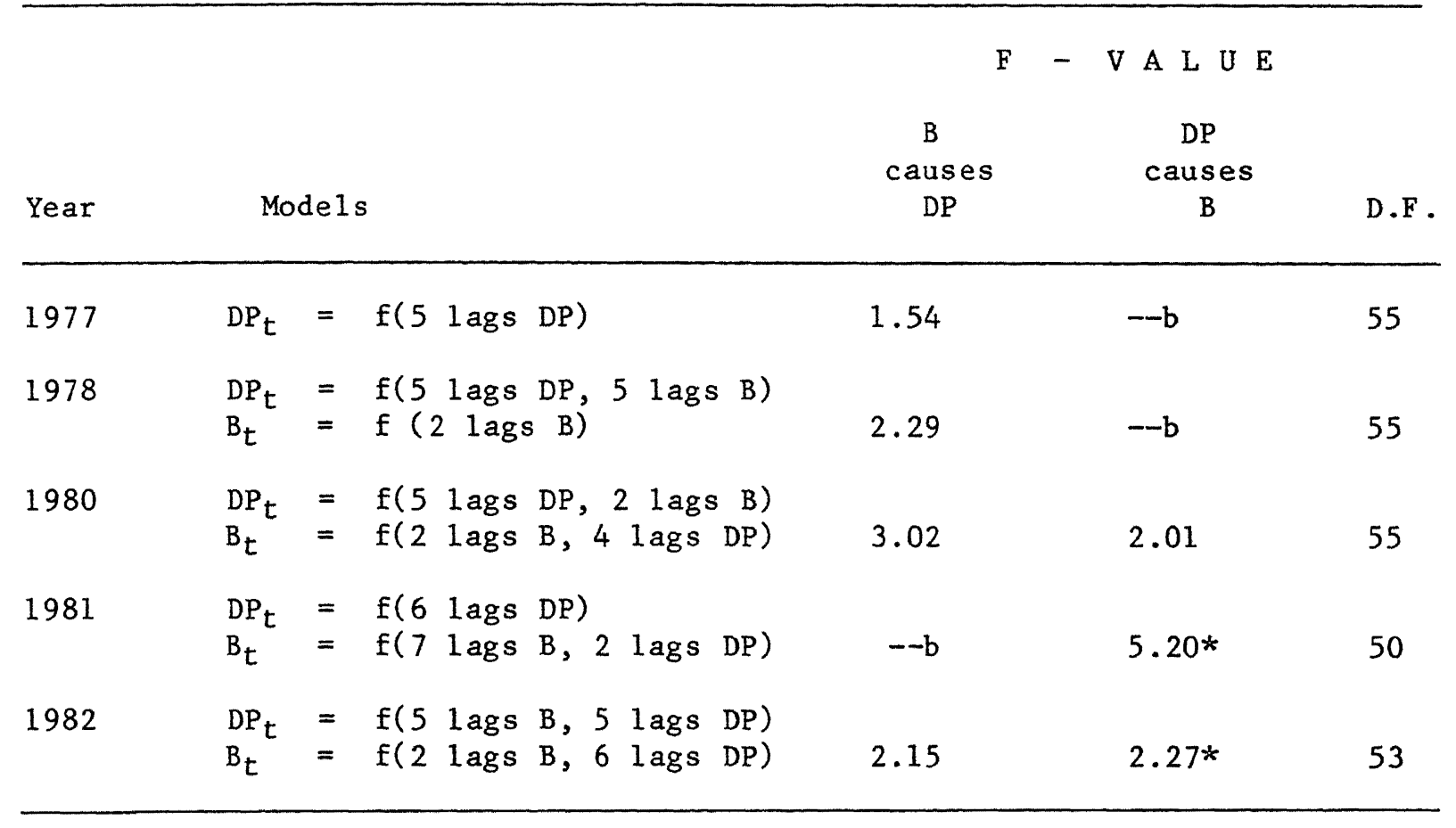

a 1979 data excluded because of data omissions.

b F-tests not calculated for models with insignificant individual lags for independent variable.

c 1977 Basis - DP sales causal relationship is not analyzed because filtering process did not establish a while noise series.

* F statistic is significant at the .05 level. 
Table 3: DP Corn Chargesa for an Ohio Elevator for Selected Dates $1977-82^{b}$

\begin{tabular}{|c|c|c|c|c|c|c|}
\hline \multirow[b]{2}{*}{ Year } & \multicolumn{2}{|c|}{ OCTOBER } & \multicolumn{2}{|c|}{ NOVEMBER } & \multicolumn{2}{|c|}{ DECEMBER } \\
\hline & Fixed & Var. & Fixed & Var. & Fixed & Var. \\
\hline 1977 & 22 & 0 & 24 & 2 & 6 & 1.5 \\
\hline 1978 & 10 & 2 & 7 & 2 & 0 & 2 \\
\hline 1980 & 15 & 3 & 20 & 3 & 15 & 3 \\
\hline 1981 & 0 & 0 & 10 & 3 & 5 & 3 \\
\hline 1982 & 12 & 3 & 7 & 3 & 0 & 2 \\
\hline
\end{tabular}

a All charges expressed in cents/bu./month.

b 1979 excluded. 


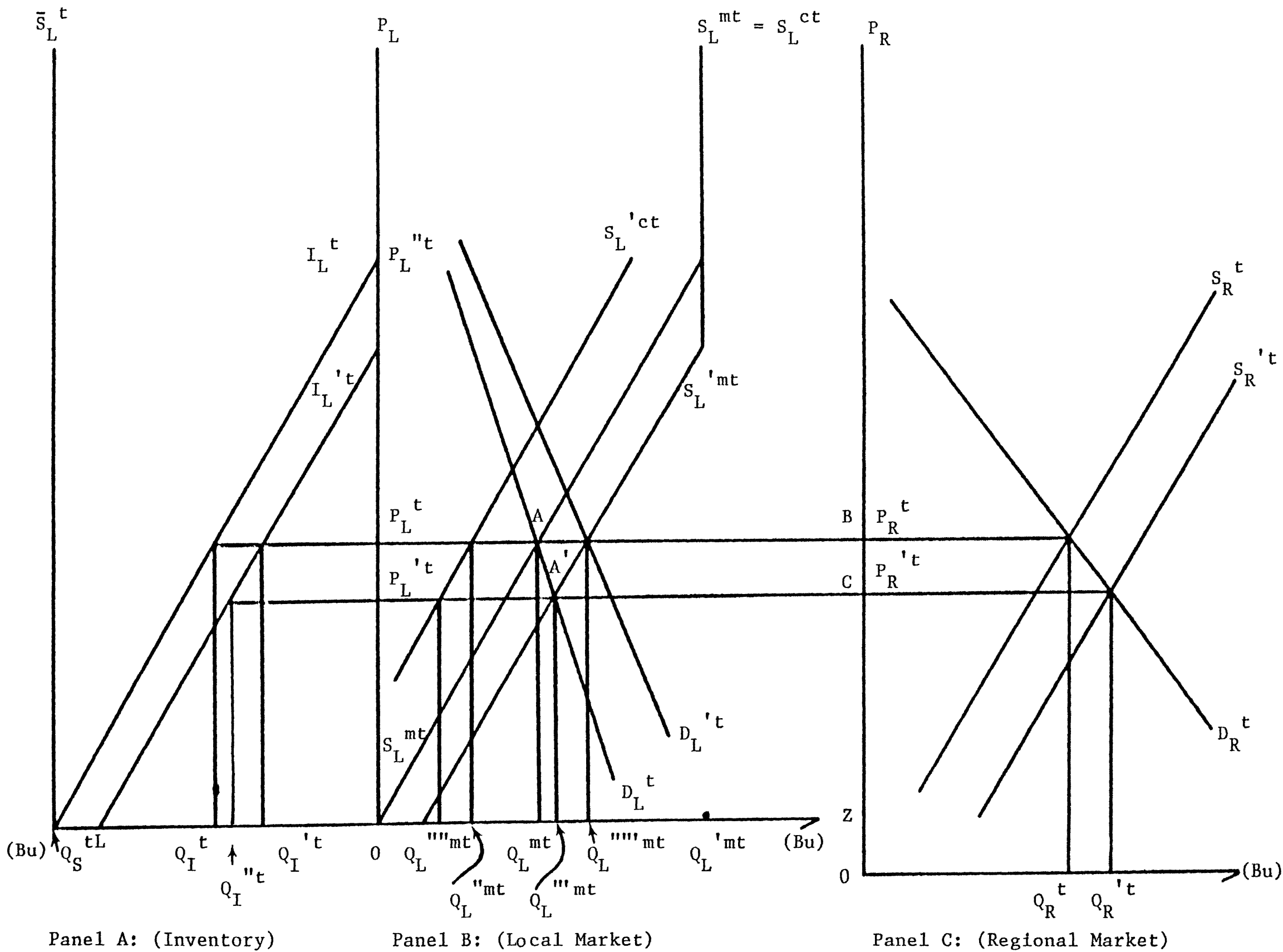

Figure 1: Hypothesized Efficiency Effect of DP on Local and Regional Market Equilibrium 
Figure 2. Change in Basis as a Function of DP

Cents per bushel for 1981 and 1982

Cents per bushel

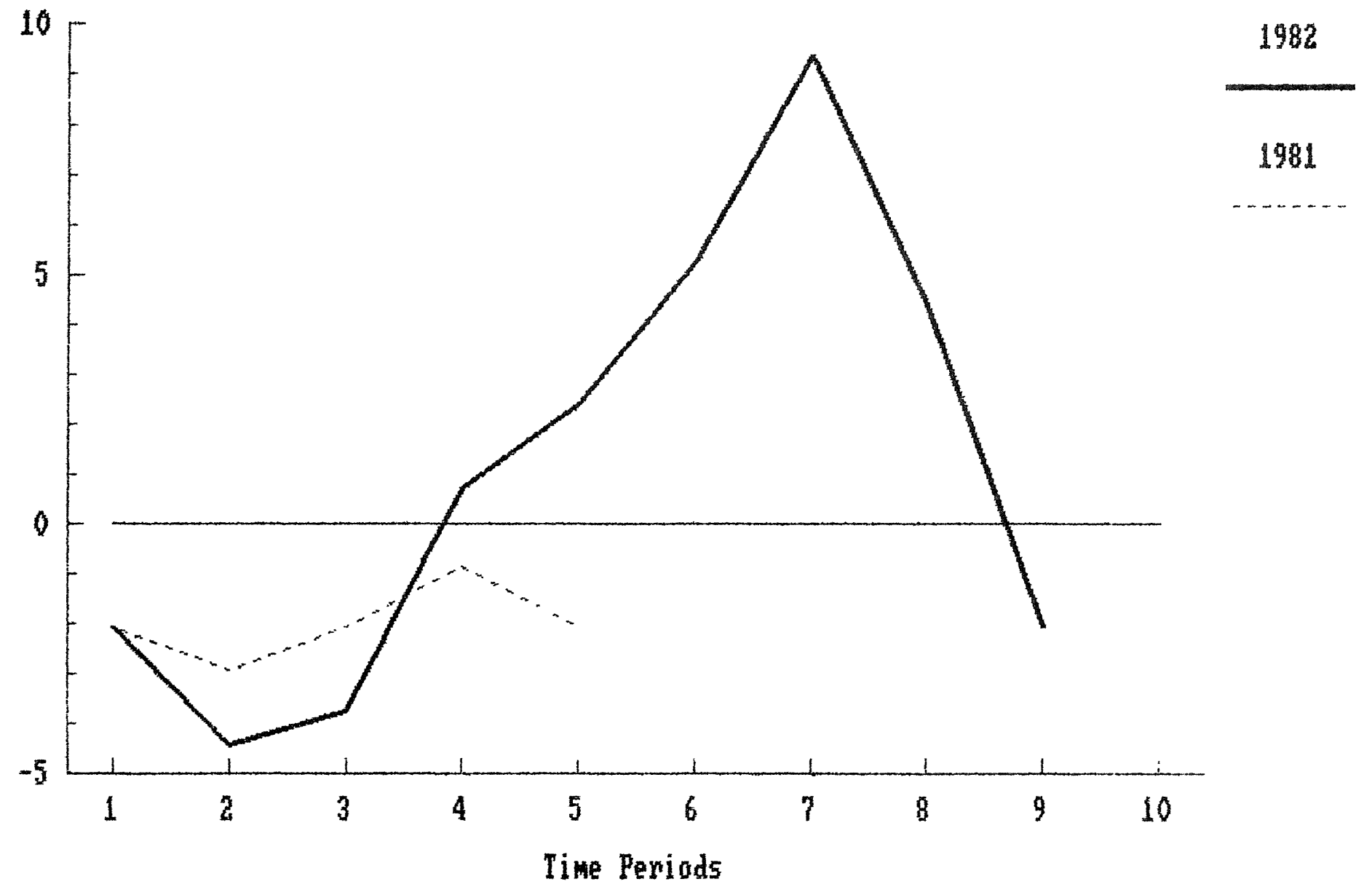

